\title{
False positive immunoreaction in products of conception
}

\author{
F G Barker, P Ozua, S Van Noorden
}

Department of
Histopathology, Royal
Postgraduate Medical
School, Du Cane
Road, London
W12 ONN
F G Barker
P Ozua
S Van Noorden
Correspondence to:
Miss S Van Noorden
Accepted for publication
10 May 1994

Department of

Histopathology, Roya

School, Du Cane

Road, London

W12 0NN

F G Barker

Miss $S$ Van Noorde

10 May 1994

\begin{abstract}
False positive immunostaining for cytomegalovirus in products of conception was revealed using an avidinbiotinylated peroxidase complex. The cause was shown to be endogenous biotin. The use of a non-avidin-biotin method avoided the problem.
\end{abstract}

\section{(f Clin Pathol 1994;47:1118-1119)}

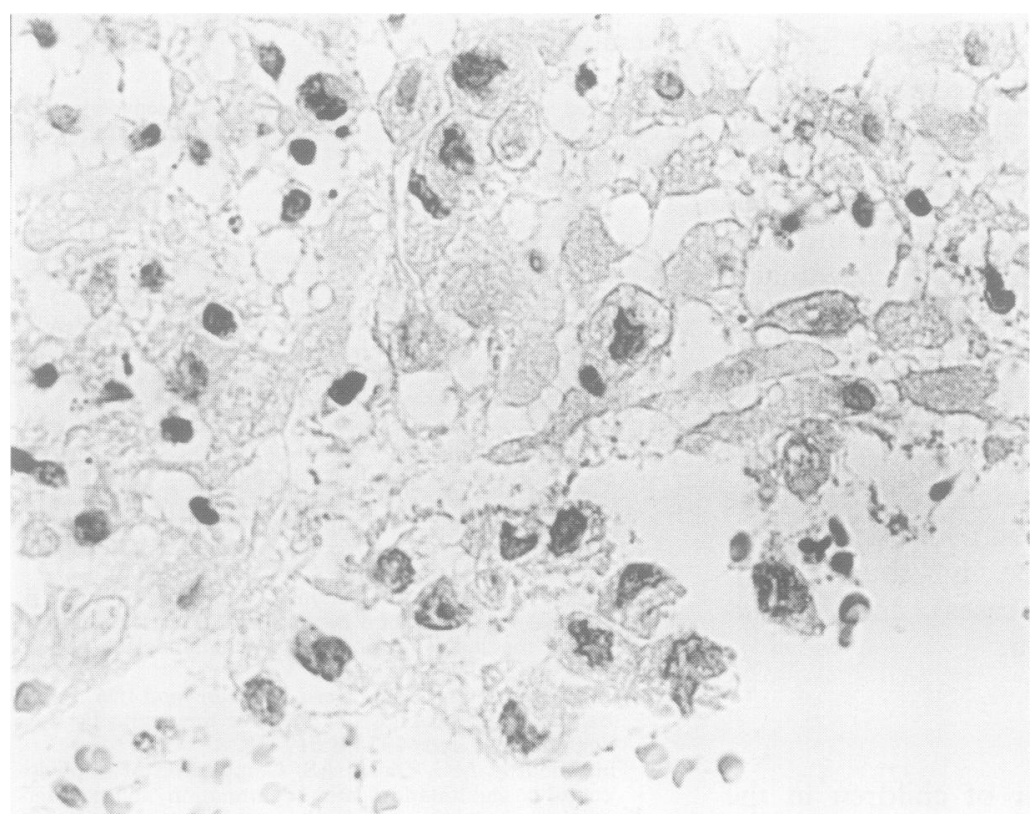

Figure 1 Superficial cells of secretory endometrium with enlarged nuclei from a case of missed abortion.

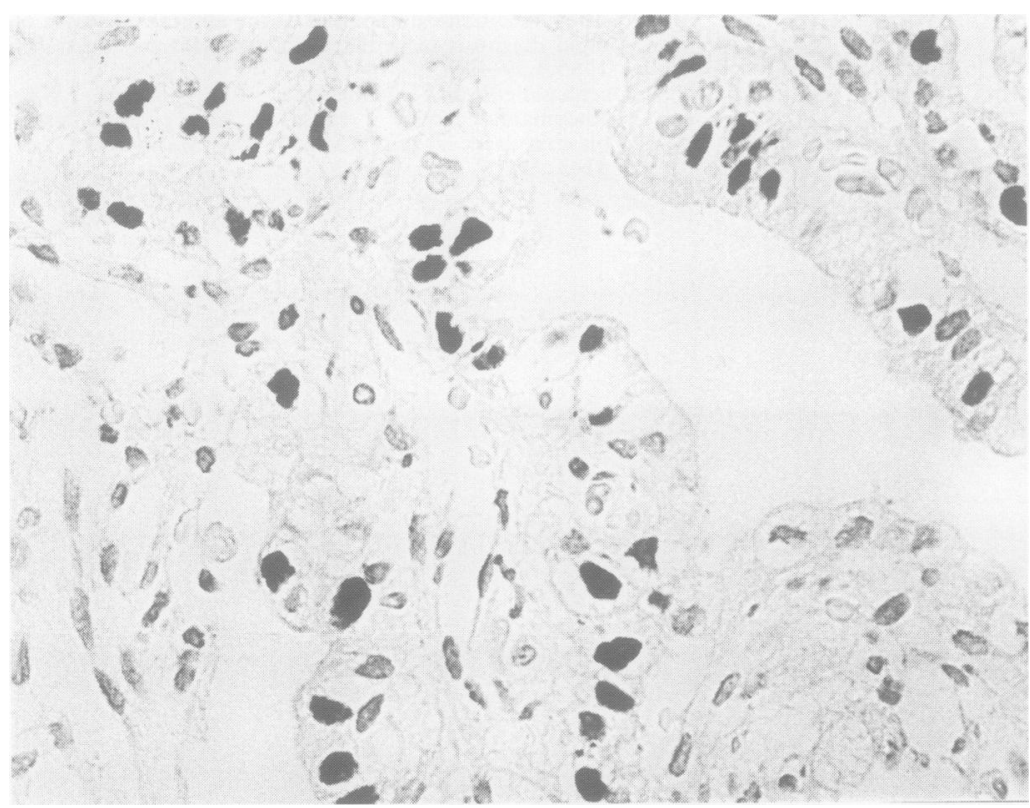

Figure 2 Immunoperoxidase stain using the $A B C$ method for detecting $C M V$ in the same case as fig 1 .
It is established practice when seeking evidence in histological sections of infection by cytomegalovirus (CMV) to supplement morphological examination by immunohistochemical staining.

Evacuated retained products of conception are common surgical specimens in this department. Recently, we examined sections of such a specimen from a case of missed abortion in which several of the nuclei of the secretory endometrium were enlarged and amphophilic (fig 1). Although the appearance was not typical of CMV infection, we wished to exclude that possibility and therefore performed immunostaining for CMV.

\section{Methods}

Paraffin wax embedded sections $(3 \mu \mathrm{m})$ from formalin fixed tissue were used. Endogenous peroxidase was blocked by incubating the tissue for 30 minutes in $0.3 \%(w / v)$ hydrogen peroxide in water. The primary antibody to CMV was a mouse monoclonal antibody (Dako, High Wycombe, UK; catalogue no. M757) diluted 1 in 100 in $0.01 \mathrm{M}$ phosphate buffered saline (PBS), $\mathrm{pH} 7 \cdot 2$, containing $0 \cdot 1 \%(\mathrm{w} / \mathrm{v})$ bovine serum albumin and $0.1 \%$ $(\mathrm{w} / \mathrm{v})$ sodium azide. The antibody diluent was used instead of the primary antibody as a negative control. The tissue was then incubated overnight at $4^{\circ} \mathrm{C}$. Binding was revealed by biotinylated goat antimouse immunoglobulin (Dako; catalogue no. E 433), diluted 1 in 500 in PBS, and streptavidin-biotinylated peroxidase complex (ABC); (Dako; catalogue no. K 377). Peroxidase was developed in PBS containing $0.03 \%(\mathrm{w} / \mathrm{v})$ hydrogen peroxide and $0.025 \%(\mathrm{w} / \mathrm{v})$ diaminobenzidine tetrahydrochloride dihydrate (Aldrich Chemical Company, Gillingham, UK; catalogue no. 26, 189-0). Nuclei were lightly counterstained with haematoxylin. In the light of the preliminary results further investigations were carried out, substituting a mouse peroxidase anti-peroxidase (PAP) complex (Dako; catalogue no. $P$ 850), diluted 1 in 100 in PBS, for the $A B C$ reagent.

\section{Results}

The nuclei of some of the endometrial cells were strongly positive (fig 2), but similar staining was found in the negative controls in which PBS had been substituted for the primary antibody (fig 3). We then demonstrated the same staining in the absence of primary antibody in five of seven cases of evacuated products from missed abortions retrieved from the surgical file. Application of the ABC 


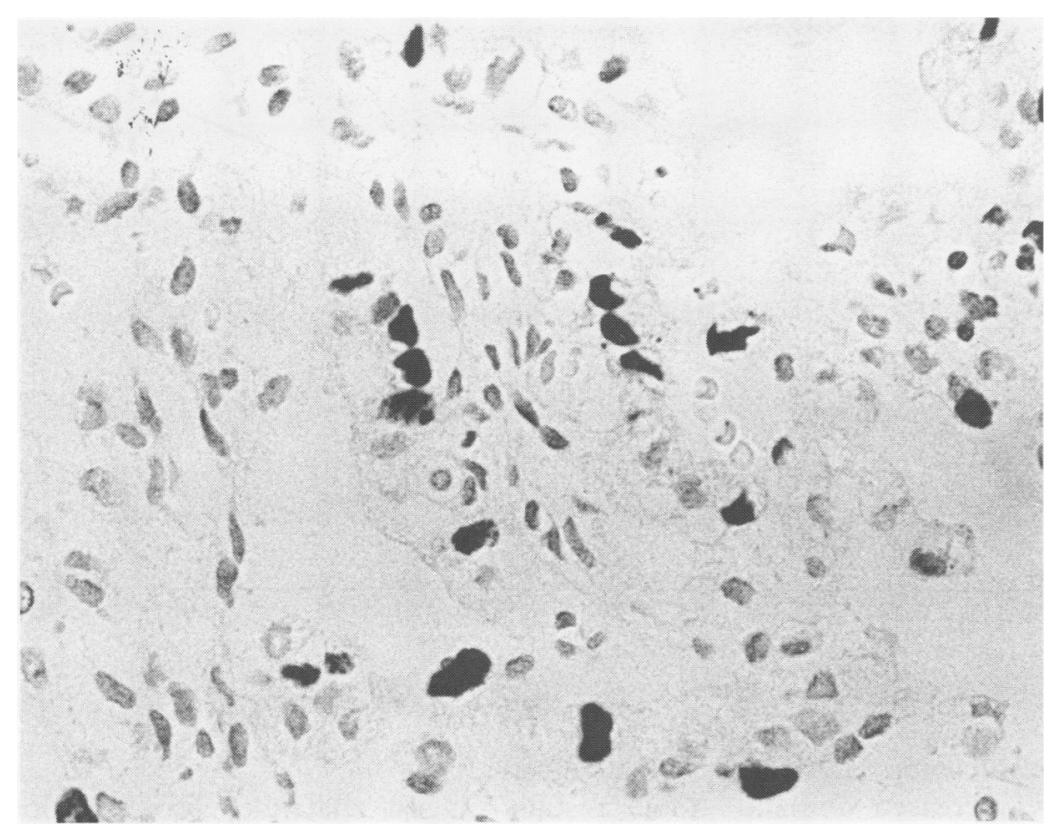

Figure 3 Negative control (PBS substituted for antibody to CMV) in the same case as fig 1. the enzyme development solutions alone or substitution of a PAP complex for the streptavidin or avidin containing reagent did not produce nuclear staining, although control CMV containing sections showed typical positive staining with the PAP method.

\section{Discussion}

We believe that the nuclei of endometrial epithelial cells sometimes contain biotin during and shortly after gestation. Biotin may take the form of intranuclear inclusions, which increases the resemblance to viral infection. This topic has already been discussed in the literature ${ }^{1}$ but as it seems to be little known, we would like to emphasise the importance of including negative immunostaining controls. We advise that methods employing avidin be avoided when immunostaining gestational endometrium for CMV.

reagent alone or of peroxidase linked avidin (Dako; catalogue no. P364), diluted 1 in 500, or streptavidin-biotinylated alkaline phosphatase complex (Dako; catalogue no. K 391 ) produced the same result. Incubation in
1 Yokoyama S, Kashima K, Inoue S, Daa T, Nakayama I, Moriuchi A. Biotin-containing intranuclear inclusions in endometrial glands during gestation and puerperium Am f Clin Pathol 1993;99:13-17.

\title{
Comparison of two automated quantitative immunoassays for the determination of $\mathrm{C}$ reactive protein concentrations
}

\author{
E A Barclay, J E Coia, P C D Kale, R G Masterton
}

\begin{abstract}
Two quantitative, automated methods for the determination of $\mathrm{C}$ reactive protein (CRP) were compared: turbidimetry (Cobas Fara II, Roche, Welwyn Garden City, UK) and fluorescence polarisation TD , Abbott, Wokingham, UK). One hundred and twenty routine serum samples submitted for measurement of CRP were tested using both procedures. The results were compared using regression line analysis and showed a high degree of correlation $\left(r^{2}=0.99, \quad X\right.$ coefficient $=$ $1 \cdot 01$, constant $=0 \cdot 11)$. $C$ reactive protein can be accurately measured using the automated turbidimetric method which can be recommended as an alternative to fluorescence polarisation.
\end{abstract}

(F Clin Pathol 1994;47:1119-1120)
Serum C reactive protein (CRP) concentrations rise and fall rapidly as part of the "acute phase" response. ${ }^{1}$ Despite the nonspecific nature of this response, CRP measurement provides a sensitive indicator of inflammation in a variety of conditions and is an objective index of the clinical response. ${ }^{2}$ Early studies of the clinical use of CRP measurement were dogged by a lack of standardisation and of quantitative assays which could be performed quickly and conveniently. Recently, an international reference standard for proteins in human serum has been published. ${ }^{3}$ This, coupled with the availability of rapid, automated and quantitative assay systems, has facilitated the development of CRP measurement as a routine clinical laboratory investigation.

Fluorescence polarisation ${ }^{4}$ is currently in widespread use, while the alternative method,
Correspondence to: Dr J E Coia

Accepted for publication 10 May 1994 